\title{
PSYCHOLOGICAL SUPPORT OF FAMILIES OF CHILDREN WITH SPECIAL NEEDS IN THE CONDITIONS OF THE COVID-19 PANDEMIC
}

\section{Prokhorenko L. I., Kostenko T. M.}

\section{INTRODUCTION}

The emergencies caused by COVID-19 have a powerful negative influence on the mental health of people affected by them.

Often this influence reaches pathogenic levels and causes the formation of a number of mental and behavioral disorders, social maladjustment, which, particularly, include: sharp reactions to stress, various disorders of adaptation and behavior, persistent changes in the mental state of the person, etc.

The research of social processes confirms the origin of new pressing difficulties and problems in family communication, which adults and children encounter in their life during crisis situations.

These difficulties are shown at the micro-social level in violations of extra-family relations.

The psychological characteristics of stress in family relationships are influenced by changes in the emotional-volitional and personal spheres of both children and parents.

The experience of practical scientists indicates an increase in the number of cases of misunderstandings, conflicts, domestic violence in families, both during the deployment of a crisis situation and after its completion.

Analysis of psychological and pedagogical research shows that the main attention in social isolation caused by the COVID-19 pandemic was provided mainly to distance learning, in particular, in the works of domestic and foreign researchers who considered the pedagogical interaction of distance learning participants: as communication in teaching (O. Bodalov, I. Zimnya, S. Kondratieva, etc.); as an essential characteristic of the pedagogical process (V. Slastyonin); as a complex of pedagogical situations (A. Boyko, I. Zyazyun, L. Kramushchenko, I. Krivonos and others), etc.

Since at the present stage of development of the distance learning system, the main focus is on the development of tools for this system, the issues of interaction between the subjects of such an educational process and the issues of organizing the distant form of psychological and pedagogical support of families in forced isolation have not received sufficient bases yet.

At the same time, the conducted scientific search indicates that in such circumstances the most vulnerable category of the population are children with special needs, and their families who do not receive appropriate special 
support, which affects negatively both the development of these children and domestic family interaction in the family. At present, there is not only little research on training, education and socialization of children with special needs, but there are no works and developments regarding the forms and methods of distant support for such children and their families.

Consequently, one of the pressing problems associated with the organization of distant psychological support for families of children with special educational needs is the development of a distant psychological support system in conditions of social isolation caused by the COVID-19 pandemic.

The goal of research is to develop a system of distant psychological support for families of children with special educational needs under the conditions of the COVID-19 pandemic.

In work with children with special needs, an important condition for correcting the development of a child, his education and social adaptation is special psychological and pedagogical work, the lack of which is especially acute during periods of crisis situations caused by various factors, in particular, the introduction of quarantine in the country, military actions, etc., when families do not have the opportunity to receive support from specialists. And, as a rule, some families, in the process of overcoming the difficulties that their child has, rely only on their own strengths, accompanied by withdrawal, maladjustment in society, others receive nonprofessional support, communicating with such families or using advice from other parents who may be false in their case.

In view of this, the development and inoculation into practice of a system of distant psychological support for families of children with special needs who are in isolation is certainly relevant.

In any crisis situation, a distant form of psychological support is an innovative form of support based on both the best traditional methods of support and new information and interactive technologies.

Along with this, this form of support is available to the wide sections of the population, regardless of material support, place of residence and health status.

\section{Theoretical aspects of the problem}

In Ukraine there are about 165000 children with special educational needs. Taking into account such statistics, special attention is paid to studies on constructing strategy for providing psycho-pedagogical and social rehabilitation support to children with special needs and their families, in particular: the development of a system of psycho-pedagogical support of children with special needs and their families (K. Babak, O. Babyak, N. Babkina, T. Kalinina, A. Kapska, V. Kobylchenko, I. Pesha, L. Prokhorenko, G. Sokolova, O. Tokar, etc.); creation of a special correctional and developmental environment for children with special needs (N. Batasheva, O. Vasylkova, M. Hrynchuk, I. Yokobauskaite, T. Kostenko, 
O. Mamicheva, O. Mozolyuk-Konovalova, O. Orlov, I. Rodygina, A. Savitsky, etc.).

A lot of research and practical developments are devoted to the integration of children and youth with special needs into the general educational space, first of all, this refers to the personal orientation of education and the creation of equal opportunities for children and youth to receive quality education; ensuring the variability of obtaining basic or complete general secondary education in accordance with the abilities and individual capabilities (V. Zasenko, E. Klopota, O. Romanenko, G. Sokolova, N. Sofiy, A. Shevtsov, N. Yarmola, etc.) ${ }^{1}$.

The result is the developed models of distance learning for such individuals in quarantine conditions, which allow to work at home with the whole class under the guidance of a teacher, who, in turn, can become a speaker for parents in helping them master the methods of acquisition of educational knowledge.

A lot of activities are being carried out to train specialists to provide psychological support to families upbringing children with special needs: special trainings and supervisory support groups are held for psychologists, social care teachers and representatives of other related professions; methodological materials of an informative and educational nature, etc. are developed and distributed (mainly through social networks).

However, there is an urgent need to develop complex psychological support for families of children with special needs in social isolation and to develop the distant models of psycho-pedagogical and rehabilitation patronage, which will include not only consulting, but also psychocorrectional and psychotherapeutic methods and procedures.

As practice shows, psychological support to families of children with special needs, as a rule, is provided in conditions of an acute shortage of time, with a lack of correctional and diagnostic capabilities.

These facts make us to say that the issues related to the provision of psychological support to families of children with special needs in crisis situations, who are in isolation, cannot continue to remain within the framework of providing single support to parents or children, but distant system of psychological support for the whole family should be developed.

In situations of isolation, the psychological problems of different families can have different consequences. In some families, psychological problems do not take on a pivotal role, in others they are the main ones.

Some psychological problems are easy to solve and do not need the exterior help, others can be related with many complications and require the intervention of specialists.

${ }^{1}$ Zasenko, V., Prokhorenko, L. Educational Development Priorities for People with Special Needs in Ukraine. / Education: Modern Discourses, 2019. (1). C. 161-167. DOI: 10.32405/2617-3107-2018-1-15. 
Among latest, there are problems of families upbringing children with special needs.

Such families are feeling discontent (deprivation) of basic needs, first of all, safety; they are experiencing a situation of uncertainty.

In addition, in these circumstances, different needs of the child can be deprived: the need for a certain amount, variability and type (modality) of stimuli; the need for basic conditions for efficient tuition; the need for primary social relations (especially with the mother), which provide the possibility of effective integration of the person; the need for social self-realization, which provides an opportunity to master various social roles and value goals, etc.

Therefore, in psychological work with families of children with special needs, it is important to take into account the specific needs of both parents and children. Such work should be based on determining basic needs, as well as their further satisfaction through cooperation with various subjects of social, rehabilitation and psychological activities. And this requires from the psychologist not only high theoretical and practical training, but also deadly concentration, a sense of responsibility, the ability to make independent nonstandard decisions quickly ${ }^{2}$.

In this context, the psychologist "accompanies" parents, providing them with the necessary methodological tools for working with children in crisis situations, and parents, in turn, master the tools for effectively helping their own children in developing the ability to change in response to a stressful situation.

The main hypotheses of the research:

1. The appearance of deprivation, as a certain mental state, is due to the living abilities of the individual in conditions of long-term deprivation or significant limitation of the ability to satisfy pivotal needs. Presently, in psychology, emotional deprivation is studied intensively, an insufficient opportunity to establish intimate emotional relationships with family members or the breakdown of an emotional bond, if such has already been created.

A bright example is a maternal deprivation, which shows in the deprivation of a child's maternal care, attention, love and tenderness.

It causes the disorders, first of all, in the emotional-volitional sphere of the child, leads to a decrease in the child's contact and suchlike. In addition, there is also distinguished a paternal (parental) deprivation. In childhood, it can also lead to developmental disorders of the child, but in a slightly different way - a violation of the formation of role-based life principles and dispositions.

2. The delivery and upbringing of a child with certain developmental disorders entails the emergence of a complex of negative reactions and experiences in the parents, such emotional states that can be described as

2 Drozd, L.V., Bystrova, Yu.O. Features of communication of adolescents with intellectual disabilities in the interpersonal relations. / Insight: the psychological dimensions of society. 2020. (3), C. 123-133. DOI: 10.32999/2663-970X/2020-3-9. 
crisis ones, related to: emotional depression, depressive tendencies, situational and personal anxiety.

The consequences of these states are: an existential crisis, cognitive disorientation of parents, latent self-destruction of parents, a crisis of their self-identification, loss of life prospects, disharmonious relationships in the family, parents' "escape" to work or self-denial as a result of an overvalued attitude towards a child, social isolation.

3. Families upbringing children with various developmental disorders can be classified as families in which the performance of basic functions has a deformed character.

Dysfunctional symptoms typical for such families caused by a developmental disorder or a child's illness and showed in the form of tension - dissatisfaction, stress, feelings of guilt, powerlessness, etc.

It is the dysfunctional family that determines the development and strengthening of the child's maladjusted ways and forms of interaction with the environment, the formation of social vulnerability in critical life situations (victimhood), becoming a victim of unfavorable conditions of socialization (victimization).

4. The child repeats consciously and unconsciously the "image" of the family: interaction models, conflict resolution, ways to overcome difficult situations, etc. In families with "chronic" problems, there is a high risk of transferring by children of behavior patterns, parental lifestyles and, accordingly, increased victimhood and victimization.

A victim person in a situation of interpersonal interaction is characterized by a position of intolerance at the same time as making hasty, rash, bipolar decisions.

The child's reactions to the events of the external world become stereotyped with time: the analysis of situations occurs according to a wellestablished scenario, which eliminates bad worrying, thoughts and feelings, protects against overload and helps to solve the problem as usual.

5. Based on the assumption that difficult life circumstances (now a long quarantine) are deprivation factors and one of the forms of a personality's life crisis, which covers its inner "I" and leads to a loss of the sense of integrity and authenticity of "I", the latter predetermines the choice of methods of psychological support for families of children with special needs within the framework of the humanistic, phenomenological systemic and subjective approaches.

The integration of the methods of these theoretical approaches will make it possible to neutralize and further prevent the consequences of deprivation due to the development of a distance model of psychological and methodological work, which provides for the use of not only consultative as psycho-correctional and psychotherapeutic methods and procedures.

The theoretical and methodological basis of the research was the following: system approach (L. Burlachuk, G. Kostyuk, O. Leontiev, 
S. Maksymenko, V. Petrovsky, S. Rubinstein, V. Tatenko, etc.); subjective approach to the study of personality (K. Abulkhanova-Slavska, A. Brushlinsky, V. Znakov, Z. Karpenko, I. Popovych, S. Rubinstein, etc.); conceptual provisions of remedial and special education and psychological support (O. Bondarenko, L. Burlachuk, A. Dushka, L. Karamushka, V. Kobilchenko, I. Omelchenko, V. Panok, L. Prokhorenko, A. Sokolova, T. Yatsenko, etc.); a humanistic approach to psychocorrection of personality (G. Ball, A. Maslow, K. Rogers, etc.) ${ }^{3}$.

Conceptual model of remote psychological support for families with children with special needs

The difficulty of understanding the concept of remote psychological support for families of children with special needs is due to its use as an innovative, conceptual idea, the implementation of which is complicated by such problems as: narrow understanding of remote support as a mechanism of tangible assistance and introduction of remote psychological support special needs is difficult, because this form stands out from the generally accepted norms of traditional management of the support process.

But the main difficulty, in our opinion, is the problem of developing a conceptual model of remote psychological support for families of children with special needs who are in social isolation, the implementation of which in practice will give this activity a coherent and comprehensive nature.

We consider psychological support as a process and a method. The method is a practical component in which the support process is carried out, which is based on the unity of three functions: diagnostic, informational, advisory.

Psychological support as a process focuses on the positive aspects and preferences of families, which help to restore faith in themselves and their abilities of parents of children with special needs, increase children's resilience to destabilizing external and internal factors, identify ways to prevent destructive, self-destructive development in interpersonal relationships.

That is, in the context of psychological service, is defined as a system of distance professional activity of a psychologist, which aims to create psychological conditions for emotional well-being, successful interpersonal relationships in families between parents and children, and child development with special educational needs.

In our opinion, to study psychological support in isolation is ineffective, because only systematically, interpreting it as a process, and as a method, and as a type of activity of a psychologist, we can create a holistic technology of remote support of families with special needs in social isolation, conditions for the harmonious development of the family as a whole.

By model we mean an abstract expression of the basic essence of an object, which is seen as the construction of certain symbols of our experience or

\footnotetext{
${ }^{3}$ Попович І.С. Психологія соціальних очікувань особистості : автореф. дис. ... докт. психол. наук : 19.00.05. Сєвєродонецьк, 2017. 44 с.
} 
thinking in a way that results in a systematic representation of that experience and thinking as a means of understanding or explaining them. By technology we mean an ordered set of actions, operations and procedures that instrumentally ensure the achievement of the predicted result.

Remote psychological support for families of children with special needs is a holistic system. Like any system, it consists of certain components that cannot exist separately, they are all interconnected.

The first component is a systematic monitoring of the psychological and pedagogical status of all family members in accordance with their current state and prospects for harmonization. To monitor the dynamics of indicators, this procedure should be repeated as often as possible. To track status, it is necessary to have clear parameters that need to be studied and researched, as well as certain standards for assessing the condition of a particular family member; have the appropriate methodological tools at their disposal; be able to monitor the status of the same parameters.

The second component is the creation of psychological conditions for the harmonization of family relations between parents and children. The creation of such conditions is carried out both in the course of direct work of the attendant with the attendant. The psychologist conducts developmental classes, organizes a special developmental psychological environment, and advises on topical issues, and indirectly - through counseling and methodological assistance to parents. The common goal of all forms of work in this direction is to create conditions for the development of a child with special needs in conditions of isolation and harmonization of family relations, which would take into account the potential, psychological characteristics of all family members, their current interests and needs.

The third component is the creation of special psychological conditions for the prevention of social crises, in particular the crisis caused by the COVID-19 pandemic.

We do not reduce this aspect of work to classical psychological care, although it is present here, because the psychologist organizes and carries out corrective, counseling work in solving problems of learning, behavior, communication or mental well-being of all family members. And, if necessary, he helps to find a specialist to provide qualified care and provides psychological support during isolation.

\section{Research methods}

Theoretical: analysis of scientific ideas and approaches regarding the problem of personality deprivation psychology, features of the development and functioning of a family upbringing children with special needs, as a system in conditions of social isolation, theoretical modeling, generalization; empirical: survey of families of children with special educational needs, diagnostic conversation, strategies for modeling family interactions, and suchlike. Among the methods of studying the family were: sociological surveys, interviews and questionnaires. 
Used methodological tools.

The interview method is to follow the sequence of the interaction. In the simplest form, there is a development of positive comments or a description of details. This method was used until the complete sequence of events was determined.

The questions were presented in an unbiased style, such as what the family is doing during the day. In addition to diagnostic significance, this technique is an essential element in the process of joining a family and gently guiding it to form a new type of behavior.

Questionnaire method (written survey). It was distinguished by sufficient validity. Various types of questionnaires were used: contact (the researcher himself organized the questionnaires and collected questionnaires), distance (questionnaires with instructions were sent by email).

Depending on the tasks, as well as features of the families, there were used the different types of questionnaires: open - contained questions to be answered; closed - possible answers were given to the questions; mixed possible answers were offered and at the same time it was possible to formulate some answers "differently".

Along with this, during the research, various strategies were used, which were divided into internal and external. The essence of these strategies was to estimate the situation in the family in the context of possible changes.

Internal strategies provided for the definition (later, formation) of an active position, which consisted in the ability to identify those conditions that can be changed, that is, the active work of family members to change the situation was noted, and also outlined the ability to identify those conditions that cannot be changed at the moment and that need to be taken for granted.

External strategies were based on the use of extra-family subsystems, such as:

- the ability to use the help of other people (neighbors, friends, other families with similar problems);

- the ability to find spiritual support (advice and help from religious leaders, to participate in the work of religious institutions);

- the ability to use the resources of government support (all kinds of support that are provided at different stages of the life cycle).

Research of models of family interactions.

Special needs children live and develop in a family where any event that happens to one person will certainly affect other family members.

Taking into account the conditions of forced social isolation, we examined the family relations in a system of four concepts: subsystems (children-parents), cohesion, adaptability, communication.

In the context of subsystem and cohesion, three types of families were found: intertwined, disconnected, and balanced. The "intertwined" families are characterized by overprotection and hyper involvement of family members in each other's lives, have a strong fear of independent actions by 
a child with special needs, which interferes with the development of the child's ability to act and live independently. On the contrary, in "disconnected" families the involvement of some members of the family in the life of the child and those around him can be minimized. (For example, the father avoids marital and parental interactions due to the developmental delays of the child). In families that have a balance between "intertwining" and "disconnecting", the family members are capable of both close ties and certain autonomy.

Adaptability (flexibility) was defined as the ability to change in response to a stressful situation. It was revealed that rigid families have difficulties adjusting to a new situation associated with the need to take care of a child with special needs.

For example, often the child's father does not share with his wife the severity of household chores and work to correct the child's development. In this case, taking care of the child, the mother is forced to devote all her strength to him and leave other family members without attention. Such a family is subject to dysfunctional conditions.

Chaotic families, which live without special rules and principles, often violate and change some of the rules, and move from the border of "emotional closeness and cohesion" to the border of "hostility and disunity".

In terms of the "communication", it was found that the greatest problems arise in the process of interaction and communication.

Mostly, the "intertwined" families consider a child with special needs as the only source of their own problems and thus try to reduce their own anxiety.

The presence of such a child in the family, in combination with other factors, can reduce the opportunities for family members to earn and rest. The increased pressure on one of the functions or roles affects many other functions or roles of family members that they cannot cope with, which creates additional stress for the family.

The "disconnected" families have a closed communication and are characterized by a lack of discussion and poor expression of emotions. In casual communication, in such a family, all issues, without exception, are vigorously discussed.

The balance in relationships is disturbed, parents try to avoid changes the development of the family cycle and the associated possible anxieties and losses, or, conversely, interact in a disunited, chaotic manner.

The "balanced" families function more successfully, they manage to avoid extremes, maintain a balance between stability and change, emotional unity and autonomy, between closed and casual communication.

This is shown in the design of the psychological roles of each family member, the formation of the family "we", the ability of family members to resolve contradictions and conflicts independently. 
It was also substantiated that relying only on its own strength, the family cannot meet crisis associated with the forced social isolation, especially those families that are classified as the "intertwined" and the "disconnected".

At the same time, the stay of a special needs child all the time at home, in addition to problems related to the development and socialization of such child, which requires constant correctional and developmental work, gives rise to other equally complex problems - related to family communication, cognitive dissonance in children during distance learning, problem behavior, etc.

Thus, consideration of the family crisis that appeared in the conditions of social isolation caused by the COVID-19 pandemic made it possible to develop a model of psychological assistance for families of children with special needs, adapted to the special needs of families and the developmental characteristics of children brought up in such families.

The conceptual idea of developing a system of distant psychological support to families of children with special needs is to achieve a common harmonious life, maximizing the potential of a child with special needs, as well as each family member, and the successful integration of such family into society.

\section{Practical study of the problem}

As was already mentioned, when upbringing a special needs child, in conditions of forced social isolation, the family often encounters significant difficulties.

This is usually due to the inability to receive timely correctional and developmental services of specialists in the social, personal, cognitive and emotional development of such a child, etc.

It is important to note that in crisis situations, there are more problems associated with the emotional and personal sphere of a child with special needs, which, due to development, has certain features.

These disorders are aggravated as a result of the so-called emotional deprivation, that is, with insufficient satisfaction of the need for emotional and personal contact. Because of social isolation, special needs children often have a violation of the mechanism of attraction in relationships with others, which negatively affects their mental development.

At the same time, the mechanism of communication with the family is often accompanied by behavioral problems of children and learning difficulties. In terms of pandemic this is especially acute. According to our monitoring, many children with special needs, in forced social isolation caused by the COVID-19 pandemic, occur secondary emotional disorders of a reactive nature in the form of a rootless feeling, speech communication fear, low mood, excessive vulnerability and anxiety.

All this further weakens the child's nervous system and creates conditions for the development of various neurotic states. 
It was also found that the critical period in the adaptation of families of children with special needs in social isolation begins from the 2nd month. Accordingly, during this period, the indicators on the scales of alienation, and subsequently conflict, aggressiveness and rigidity in the interpersonal interaction of parents and children overcome the threshold of average indicators towards high values.

I.e., we can talk about the imbalance that occurs during this period between the intensity of influence of the stress inducing factor (social isolation) and the adaptive capacities of the parents and deepens with the increase in the length of stay of families in these conditions. Also, there were identified the factors that determine the success of the adaptation of families in the conditions of social group isolation: activity of all family members, socio-psychological position and the adequacy of the acceptance of a social role.

These facts make us to say that the issues related to the provision of distant psychological support to families of children with special needs in crisis situations, who are in isolation, cannot continue to remain within the framework of providing single support to parents or children, but a distant system of psychological support for the whole family should be developed.

Thus, the introduction of an integrated approach to providing psychological support to families of children with special needs can be implemented by creating a model of a distant psychological support for such families, which will contain a mobile application, a virtual university for parents at a remote place, a crisis counseling line and psychological support, e-mail trust for parents, development of information materials for psychologists, parents and children.

The offered model of distant psychological support provides for systemic studies with children and families using communications and Internet resources (web quests, teleconferences, virtual discussions, etc.).

The implementation of this model will automate the child's activities using new technologies for presenting information, such as info graphics, sketching, storytelling, alternate reality, and suchlike.

The distant support system to parents will be aimed at optimizing the influence of the family on the child due to the increase in the pedagogical culture of parents, which will include: work with parents and teachers; control over the work of parents with children.

At the first stage, we intend to develop the necessary educational material for families of different types ("intertwined", "disconnected", "balanced"), using Internet tools.

The developed educational materials will be provided to parents for stand-alone use in order to ensure the educational process at home and the establishment of harmonious relations in the family.

At the second stage, based on the material provided to the parents, the psychologist analyzes their work and corrects the interaction of parents with children. 
Material for analysis is provided in the form of control and independent work, photo reports of the child's participation in project activities, etc. At the third stage, there will be the implementation of scientific, methodological, organizational, systemic and technical work to support the family as a whole.

Thus, the creation of a distant psychological support system will provide an opportunity:

1. For variable, split-level and differentiated approaches to the process of development, education and upbringing of children with special needs in the family, in conditions of isolation caused by crisis situations, taking into account their age, physiological and psychological characteristics.

The program of a distant psychological support to a special needs child in a family in crisis situations will contain psycho-correctional measures that will affect his cognitive, behavioral and emotional spheres.

Herewith, psycho-correctional work on the development of the cognitive sphere at the substantive stage will contain various cognitive methods and techniques, for example, mnemonic or heuristic, and on the methodical stage - the methods of organizing and forming cognitive activity of various operational content.

Psycho-correctional work, aimed at the emotional sphere, will have the goal of creating conditions under which the subject of psycho-correction of activity forms a positive and optimistic attitude towards himself, towards the world around him and towards his family.

The behavioral block of psycho-correctional work with a special needs child will be aimed at intensifying activity of the subject of psychological correction; in particular, it should contain recommendations for building effective behavior and communication.

2. In the context of cooperation of psychologists with parents of children with special needs, specialists "accompany" parents by providing them with the necessary methodological tools for working with children in crisis situations, and parents, in turn, master the tools for effectively helping their own children in developing the ability to change in response to a stressful situation.

I. e., the goal of the psychologists of distant psychological support should be to help parents and special needs children in the development of adaptive strengths and resources.

The key approach to the development of a model of distant psychological support for parents of special needs children will be the introduction of information and computer technologies in interaction with psychological technologies, forms and methods.

Cooperation with specialists is necessary not only for obtaining specific skills and abilities, but also for the personal growth of the parents themselves. In this context, specialists have a unique opportunity to "accompany" parents, providing them with the necessary methodological tools for working with children in crisis situations, and parents, in turn, 
master the tools for effectively helping their own children in developing the ability to change in response to a stressful situation.

3. Psychotherapeutic work with the family will be aimed at increasing the level of parental competence and enhancing the role of parents in the upbringing and education of the child. In this sense, an important direction is special psychotherapeutic work aimed at solving the parents' own personal problems. According to our observations, the most efficient is the work carried out in the form of "supervision", that is, corrective work with the child.

\section{CONCLUSIONS}

In sum, during an experimental research of the peculiarities of the influence of conditions of social isolation on families of children with special needs, it was found that without the use of special measures aimed at overcoming the psychogenic effect of social isolation conditions, negative mental phenomena arise and grow in children and parents in conditions of a pandemic, such as: deprivation of a certain block of basic personal needs, negative psycho-emotional states, feelings of loneliness and others.

The dynamic study of the occurrence of these negative phenomena shows that their intensity and the percentage of families, in which they are diagnosed, grow in direct proportion to the length of stay in conditions of social isolation.

In order to ensure an effective process of work of psychological support of families raising a special needs child in conditions of social isolation, in our opinion, it is advisable to carry out in the following areas:

- creation of a healthy moral and psychological atmosphere in families, the formation of chummy relations between parents and children, mutual assistance, overcoming sense of isolation, prophylactic treatment of psychotraumatic factors;

- formation and development of parents' psychological readiness to perform parental duties, motivational and emotional-volitional stability, the level of inner peace;

- teaching children with special methods and technologies aimed at reducing the actions of negative psychological factors, including social isolation.

Systematic and complex work of a psychologist with a family in conditions of social isolation is a boon to the formation of a positive perception by parents of their child, to the harmonization of relations in the family, which leads to step changes in the attitude of family members to each other and to their "special" child.

So, the purpose of distant psychological support is to make parents realize that they are not alone in their difficulties; there are fairly qualified specialists nearby who are ready to help at any moment.

A break new ground of further research is to identify ways to prevent cases of social isolation of families of children with special needs, to take measures 
aimed at their social rehabilitation, as well as well as the creation of a virtual university for parents, a crisis counseling line and the development of information materials for psychologists, parents and children.

\section{SUMMARY}

Today, the Ukrainian society is undergoing a tough time related to the introduction of a quarantine regime in Ukraine caused by the consequences of the COVID-19 pandemic. In such crisis situations, psychologists, psychotherapists, teachers, sociologists, demographers attest to the fact that in the field of family issues there is an increase in problems, caused by a psychological crisis in families, especially in those who are upbringing children with special needs.

The inevitable consequence of crisis situations is the destruction of the basic human need - the need for safety, the violation of a stable picture of the world. This leads to severe aftereffects: neurotization, depression, loss of faith in oneself, loss of perspective - and largely determines the further fate of not only one particular person, but also entire social groups.

Throughout the world, on the background of the pandemic and quarantine, the number of domestic psychological and physical violence has increased sharply. Public organizations of Ukraine also draw attention to this tendency. Matters of the organization of psychological support in crisis situations should provide the timely and systematic study of the specifics of the functioning of families with children with special needs and an effective psychological impact on overcoming unwanted intrafamilial states, including those associated with the threat of psychological trauma.

In this sense, systematic support to families upbringing children with special needs is important and necessary, since it affects the psychological mood of the family, forms a child's system of value orientations, perception of the world, a sense of safety and prospects for personal development.

The introduction of an integrated approach to the provision of psychological support to "special" families allows, through the optimization of the internal family atmosphere, harmonization of interpersonal, marital, parent-child relations, to solve the problems of helping a special needs child.

Therefore, under the conditions of the COVID-19 pandemic, it is important to work with the family as an integral unit, it requires the direction of psychological and socio-pedagogical work not only for the rehabilitation of the child, but also the introduction of psychological support for parents.

\section{REFERENCES}

1. Drozd, L. V., Bystrova, Yu. O. Features of communication of adolescents with intellectual disabilities in the interpersonal relations. I Insight: the psychological dimensions of society. 2020. (3), pp. 123-133. DOI: 10.32999/2663-970X/2020-3-9. 
2. Попович І.С. Психологія соціальних очікувань особистості : автореф. дис. ... докт. психол. наук : 19.00.05. Сєвєродонецьк, 2017. 44 с.

3. Zasenko, V., Prokhorenko, L. Educational Development Priorities for People with Special Needs in Ukraine. / Education: Modern Discourses, 2019. (1). pp. 161-167. DOI: 10.32405/2617-3107-2018-1-15.

Information about the authors: Prokhorenko L. I., Doctor of Psychology Sciences, Professor, Deputy Director Mykola Yarmachenko Institute of Special Education and Psychology of National Academy of Educational Sciences of Ukraine 9, Berlinsky str., Kyiv, 02000, Ukraine

Kostenko T. M., Candidate of Psychological Sciences, Head of Department of Education of Children with Visual Impairments Mykola Yarmachenko Institute of Special Education and Psychology of National Academy of Educational Sciences of Ukraine 9, Berlinsky str., Kyiv, 02000, Ukraine 